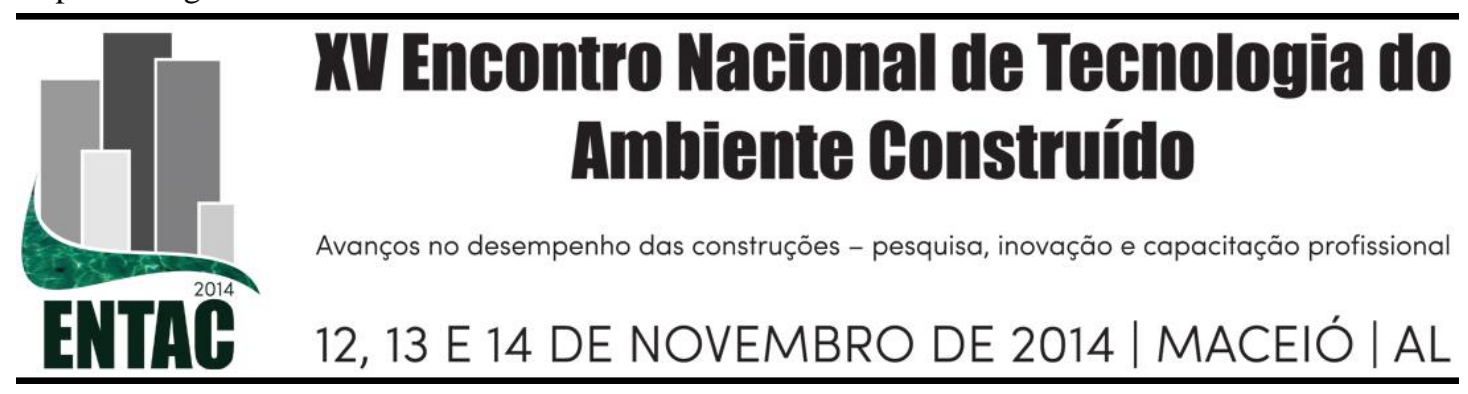

\title{
AVALIAÇÃO DOS IMPACTOS TERMO-ENERGÉTICOS DA ORIENTAÇÃO SOLAR EM HABITAÇÃO DE INTERESSE SOCIAL NA ZONA BIOCLIMÁTICA 01
}

\author{
DOERFLER, Marianna A. (1); KRUEGER, Eduardo L. (2)
}

(1) Technische Universität Kaiserslautern, e-mail: marianna.doerfler@architektur.uni-kl.de

(2) Universidade Tecnológica Federal do Paraná, e-mail: ekruger@utfpr.edu.br

\begin{abstract}
RESUMO
A necessidade de fornecer habitações dignas para a população de baixa renda brasileira é um assunto que vem sendo reforçado por diversos autores. O Programa Minha Casa, Minha Vida - PMCMV -, é uma iniciativa neste sentido, sendo um programa do governo federal por meio da parceria entre a Caixa Econômica Federal, a Prefeitura e a COHAB - Companhia de Habitação Popular. Em Curitiba, segundo o Zoneamento Bioclimático Brasileiro, classificada como Zona Bioclimática 01, o PMCMV foi implementado por meio de um convênio assinado em abril de 2009. Nesta pesquisa de doutorado, a tipologia habitacional térrea de um pavimento, construída conforme a planta padrão divulgada pela Caixa, responsável pela regulamentação federal da legislação municipal, é estudada em termos de adequação climática incluindo materiais, forma construtiva, estratégias de desenho passivo, entre outros aspectos. Como primeira etapa do processo construtivo, a implantação de uma edificação - orientação solar da fachada principal - em função de sua tipologia, posicionamento de suas aberturas, utilização de elementos de sombreamento, pode trazer consequências no desempenho termo-energético da mesma. Erros de implantação podem influenciar negativamente o desempenho esperado de algumas estratégias de desenho passivo. Na Latitude de Curitiba $\left(25,5^{\circ} \mathrm{S}\right)$ a orientação solar pode ser fundamental para a redução do desconforto térmico por frio. Neste estudo, são realizadas simulações termo-energéticas com o programa EnergyPlus da planta padrão do PMCMV, verificando os efeitos em termos de consumo energético estimado em climatização artificial - graus-hora para aquecimento - e os níveis de conforto térmico interno advindos de diferentes orientações da planta padrão incluindo uma realocação de aberturas. Resultados mostraram que, por exemplo, mudanças na orientação solar trazem como conseqüências alterações na necessidade de aquecimento de cerca de 2,6\%. Para mudanças de orientação solar acompanhadas de uma realocação de janelas, tais diferenças relativas para aquecimento chegam de 0,3\% a $2,6 \%$.
\end{abstract}

Palavras-chave: Simulação Termo-energética, Desempenho Térmico, Habitação Popular, Conforto Térmico, ENTAC 2014.

\begin{abstract}
The need for providing adequate housing for Brazilian low-income families is a subject that has been reinforced by several authors. The "Minha Casa, Minha Vida" - PMCMV -, is an initiative in this direction, being a federal program through a partnership between the Caixa Economica Federal, the Municipality and COHAB - Popular Housing Company -. In Curitiba, classified as Zone 01 in the Brazilian Bioclimatic Zoning, the PMCMV was implemented through an agreement signed in April 2009. In this PhD research, the single-storied social housing typology, built according to the standards required and according to municipal laws, is evaluated in terms of climatic adequacy including materials, construction, passive design strategies, among other aspects. As the first step of the construction process, the siting of a building (in respect of solar orientation of the main facade) depending on its typology, position of openings, use of shading elements, may have consequences on the building's thermal performance. Siting errors can negatively affect the expected performance of passive design strategies. For Curitiba's latitude $\left(25.5^{\circ} \mathrm{S}\right)$, solar orientation can be crucial for the reduction of
\end{abstract}


thermal discomfort due to cold. In this study, thermo-energy simulations of the PMCMV are performed by means of the simulation tool EnergyPlus, checking the effects on energy consumption in HVAC systems (heating degree-hours) and indoor thermal comfort levels arising from different orientations of a standard prototype with reallocation of openings. Results showed that, for example, a change in solar orientation brings about a 2,6\% change in heating demand. For solar reorientation accompanied by a reallocation of windows, heating needs can vary from $0,3 \%$ to $2,6 \%$.

Keywords: Energy Simulation, Thermal Performance, Social Housing, Thermal Comfort, ENTAC 2014.

\section{INTRODUÇÃO}

O desenvolvimento econômico do Brasil está diretamente ligado à solução de problemas sociais, dentre os quais se destaca o déficit habitacional, classificado em dois tipos: o déficit por incremento de estoque e o déficit por reposição de estoque, e que atingem principalmente as classes sociais mais pobres. Nesse sentido, segundo a concepção de desenvolvimento através da liberdade elaborada por Amartya Sen (SEN, 2007), o acesso à moradia é visto como condição para a promoção das liberdades dos indivíduos e, consequentemente, para o desenvolvimento do país.

Por essas razões, foi implantado em julho de 2009 com a Lei no 11.977 (Brasil, 2009), o Programa Minha Casa, Minha Vida - PMCMV -, cujo objetivo principal é facilitar a aquisição da casa própria pelas famílias com renda mensal entre zero e dez salários mínimos, sobretudo por aquelas localizadas nas periferias das grandes cidades. Para isso, o governo federal delegou à Caixa Econômica Federal - CAIXA - a gestão operacional do programa e dos seus recursos (D’AMICO, 2011).

A execução das obras do empreendimento é realizada por construtora contratada pela CAIXA, que se responsabiliza pela entrega dos imóveis concluídos e legalizados. Os imóveis contratados são de propriedade exclusiva do FAR e integram seu patrimônio até que sejam alienados.

Cada construtora faz sua própria planta, porém as unidades habitacionais apresentam uma tipologia de casas térreas ou apartamentos segundo as especificações mínimas dadas pela CAIXA (CAIXA, 2006) e pelo Fundo de Arrendamento Residencial - FAR -. A tipologia apresentada para cada apartamento contém minimamente sala de estar, dormitório para casal e dormitório para duas pessoas, cozinha, área de circulação e banheiro e área de serviço na parte externa.

\section{OBJETIVO}

O objetivo deste trabalho é avaliar o desempenho termo-energético de uma habitação popular aproveitando-se de estratégias passivas para a Zona Bioclimática 01 de acordo com a NBR 15220-3 (ABNT, 2003).

Foram propostas pequenas alterações em projeto em fase de planejamento da edificação, direcionadas a uma diminuição de desconforto por frio ou de redução de demanda energética para aquecimento. A Figura 1 mostra um esquema de diferentes escalas ou etapas para o planejamento de edifícios. 
Figura 1 - Esquema de etapas de planejamento

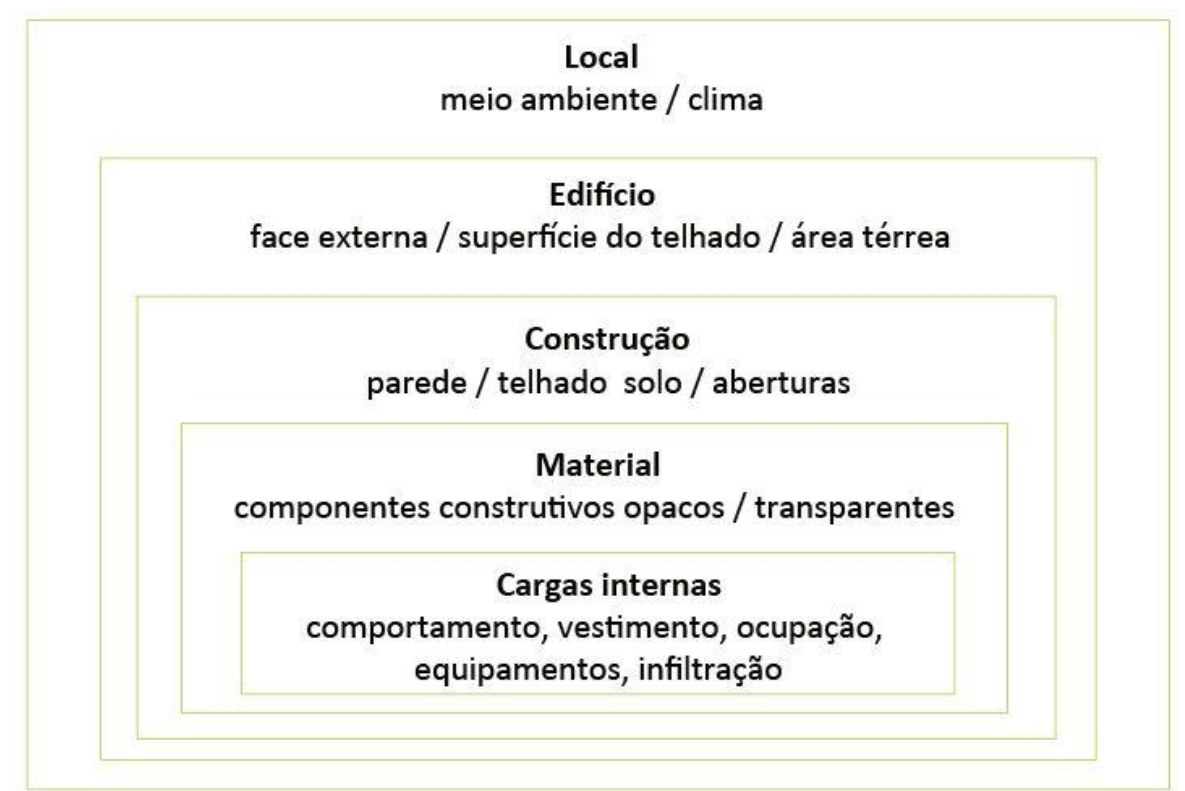

Fonte: DOERFLER (2014)

\section{OBJETIVO}

O estudo é oriundo de uma tese de doutorado em desenvolvimento (DOERFLER, 2014), que trata de uma análise sobre as estratégias passivas e energéticas para a otimização do conforto ambiental e gasto energético da arquitetura residencial do Brasil. Foram realizadas simulações termo-energéticas com o software EnergyPlus a partir de arquivos formato EPW - EnergyPlus Weather File (U.S., 2011). O EnergyPlus é um programa de simulação computacional que objetiva auxiliar o estudo e análise de edifícios do ponto de vista termoenergético. A ferramenta foi concebida pelo Departamento de Energia dos Estados Unidos a partir de programas já existentes, como o Blast e o DOE-2 (MORI; KRÜGER, 2012). O programa simula a carga térmica de uma edificação com base nas descrições e parâmetros previamente definidos pelo usuário. Assim, o EnergyPlus calcula a quantidade de energia necessária para que a temperatura do ar ambiente interior se mantenha dentro dos limites aceitáveis.

Como dados de entrada, o EnergyPlus utiliza informações como localização geográfica, geometria e materiais constituintes do edifício, zonas térmicas, arquivos climáticos, equipamentos, iluminação, pessoas e padrões de uso. Como resultados, o programa fornece dados de saída relativos a temperatura exterior, temperatura interior em cada zona térmica, necessidades de energia para aquecimento e resfriamento e trocas de calor pelos elementos da envoltória (MORI; KRÜGER, 2012). Os dados de temperatura do solo, necessários para as simulações, foram obtido do programa TRNSYS no formato climático EPW. A cidade analisada é Curitiba, a qual pertence à Zona Bioclimática 01 (ZB 01), de acordo com a NBR 15220-3 (ABNT, 2003). A edificação analisada tem como planta padrão de acordo com as diretrizes dadas pela CAIXA (CAIXA, 2006). Possui área total construída de $38,4 \mathrm{~m}^{2}$ contendo sala de estar, dormitório para casal e dormitório para duas pessoas, cozinha, área de serviço (externa), área de circulação e banheiro, como se observa na Figura 2.

O enfoque metodológico adotado neste trabalho apresenta três etapas, descritas a seguir. 
1) Simulação do caso base para a comparação;

2) Simulação para uma rotação da edificação a cada $45^{\circ}$ - avaliação dos dados de demanda de aquecimento anual $\left(\mathrm{kWh} / \mathrm{m}^{2} \mathrm{a}\right)$;

3) Simulação com reposicionamento/realocação das aberturas e rotação da edificação a cada $45^{\circ}$ - avaliação dos dados de demanda de aquecimento anual $\left(\mathrm{kWh} / \mathrm{m}^{2} \mathrm{a}\right)$.

\section{RESULTADOS}

\subsection{Caracteres}

A orientação básica da residência (fachada referência) foi adotada pelo critério de maior valor da relação window-to-wall-ratio - WWR - de cada fachada, segundo o projeto original (Figura 2), para a orientação Norte. Nesta nova situação (Figura 3), a demanda energética anual da edificação para aquecimento é de $345,11\left(\mathrm{kWh} / \mathrm{m}^{2} \mathrm{a}\right)$ e para resfriamento de $0,10\left(\mathrm{kWh} / \mathrm{m}^{2} \mathrm{a}\right)$. (Embora se trate de uma edificação com modo de operação passivo, os dados de demanda nos servem de referência na análise de desempenho.) Considerando que a demanda total anual para resfriamento é significativamente inferior à de aquecimento, a análise será feita exclusivamente sobre a necessidade de aquecimento anual na moradia.

\section{Figura 2 - Planta Padrão Casa Popular da CAIXA}

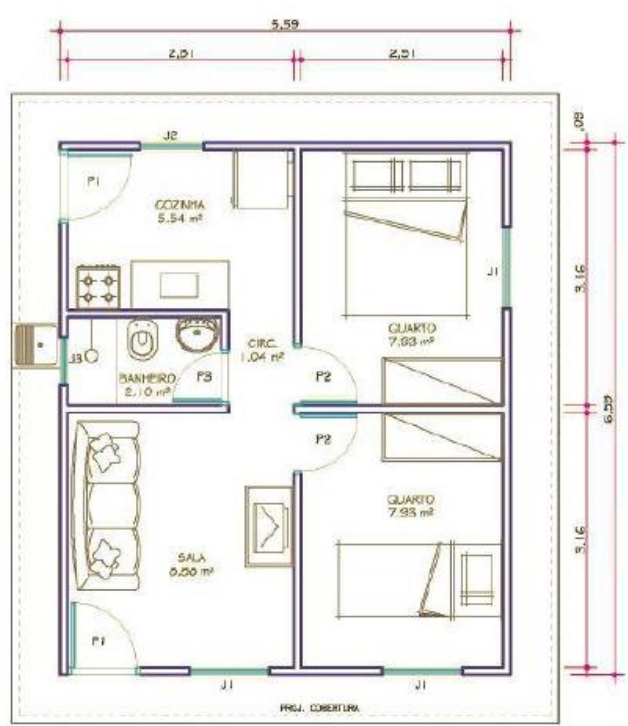

Orlavia baixallatout

Fonte: CAIXA (2006)

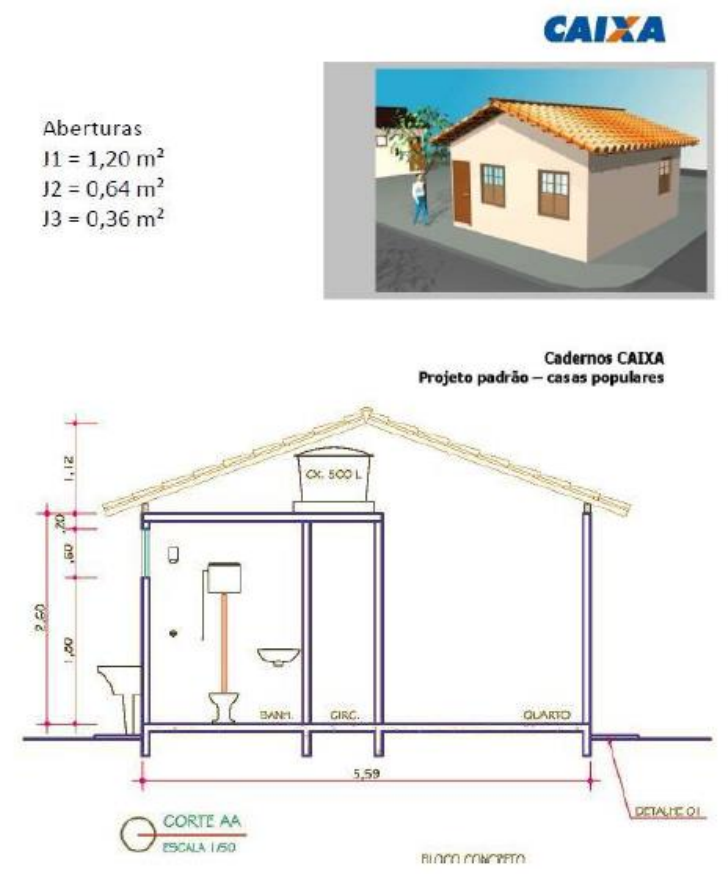


Figura 3 - Planta Padrão Casa Popular da CAIXA adotada

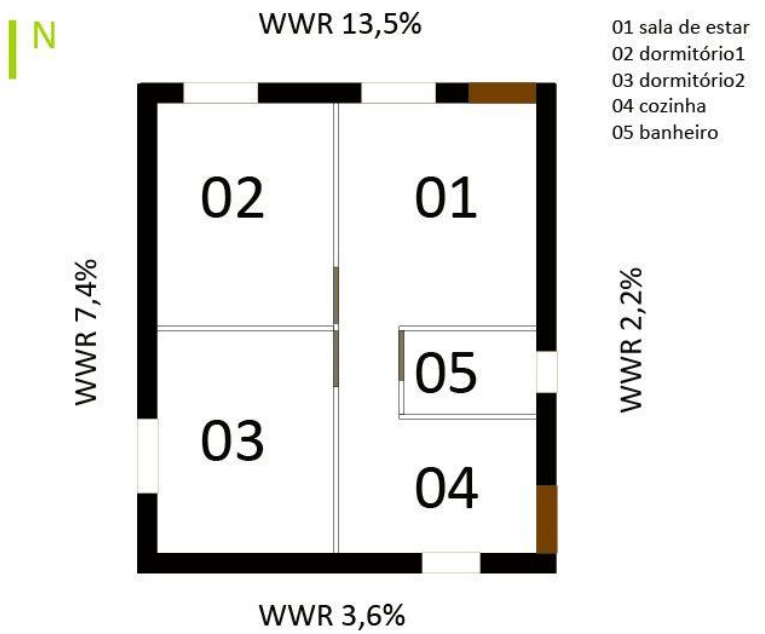

Fonte: DOERFLER (2014)

\subsection{Reorientação da edificação}

O Gráfico 1 mostra diferenças percentuais em termos relativos à pior situação, ou seja, aquela em que a demanda para aquecimento anual é mais significativa, notadamente a fachada Sudoeste (SW). Com a reorientação da residência a partir do projeto original conforme a Figura 4, ou seja, sem reposicionamento das aberturas, nota-se um pior desempenho para o quadrante Sul-Oeste $(\mathrm{S}-\mathrm{W})$, o que se relaciona com a orientação da fachada com maior percentual de abertura seja para S, SW ou W. No caso, porém, da fachada principal para Oeste (W), há menor exposição ao sol das aberturas de um modo geral para o Norte, com um WWR de apenas 2,2\% para Norte. Observe-se que o benefício de posicionar a fachada com maior WWR para Nordeste (NE) é um pouco maior do que o posicionamento dessa fachada para Norte. Entretanto, as diferenças relativas são pequenas, atingindo-se um valor máximo de 2,6\% para a fachada principal voltada à Nordeste.

\section{Gráfico 1 - Síntese dos Resultados/Diferenças percentuais em termos de}

necessidades de aquecimento em relação à pior situação, com reorientação da fachada de $45^{\circ} \mathrm{em} 45^{\circ}$
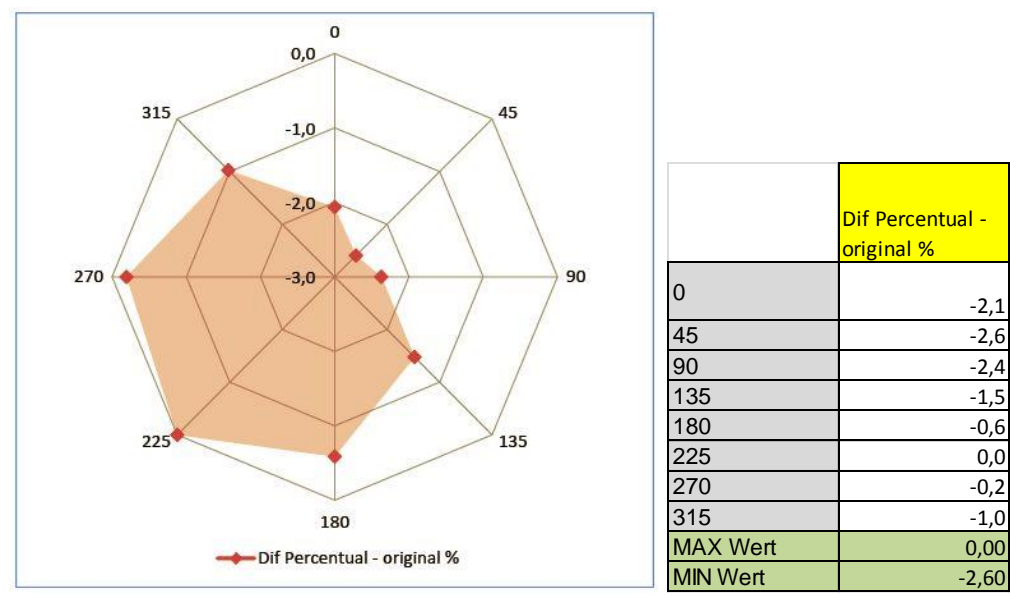

Fonte: DOERFLER (2014) 

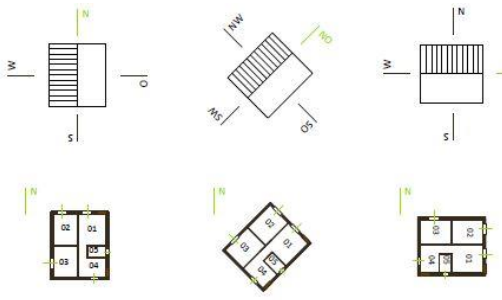

$45^{\circ}$

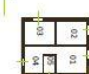

$90^{\circ}$
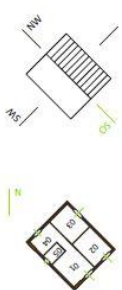

$135^{\circ}$
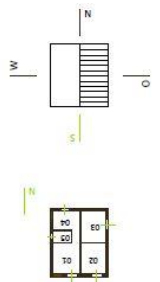
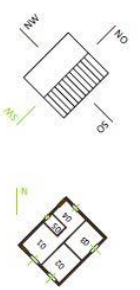

$225^{\circ}$
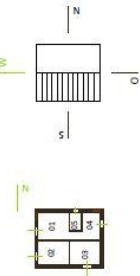

$270^{\circ}$
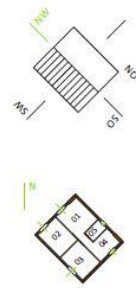

Fonte: DOERFLER (2014)

\subsection{Reposicionamento das aberturas}

Reorientaram-se algumas aberturas da edificação, obtendo-se as relações WWR alteradas por área de fachada conforme a Figura 5 e o Quadro 1. Figura Considerando as diferenças percentuais relativas à pior situação, ou seja, fachada com maior WWR para Sudoeste com posicionamento das aberturas conforme projeto original do PMCMV, a maior redução de demanda para aquecimento artificial obtida foi da mesma forma que apenas reorientando as fachadas, de $2,6 \%$.

O reposicionamento da janela dos cômodos 01 (F1) e 03 (F3) traz menor diferenciação nos resultados: a relação entre melhor e pior situação em redução da necessidade de aquecimento é, em ambos os casos, de menos de 2,2\%. A maior diferenciação se observa no reposicionamento da abertura do cômodo 02 (F2), sendo esta de 2,6\%. Por isso, uma orientação menos vantajosa na situação $\mathrm{F} 2$ pode trazer maiores consequências que nos dois outros casos. Observa-se que no caso F2 a fachada com maior comprimento contém a maior área de WWR; ao contrário do projeto original que contém o maior valor de WWR com a fachada de menor comprimento.

Contudo, as diferenças obtidas em relação à redução da demanda por aquecimento são pequenas considerando apenas uma reorientação da edificação (Gráficos 2-5). Os Gráficos 3-5 mostram em quais situações uma realocação das aberturas podem trazer inclusive prejuízos em termos de aumento da demanda, comparativamente a uma reorientação das fachadas.

\section{Quadro 1 - WWR Original em comparação com F1, F2 e F3}

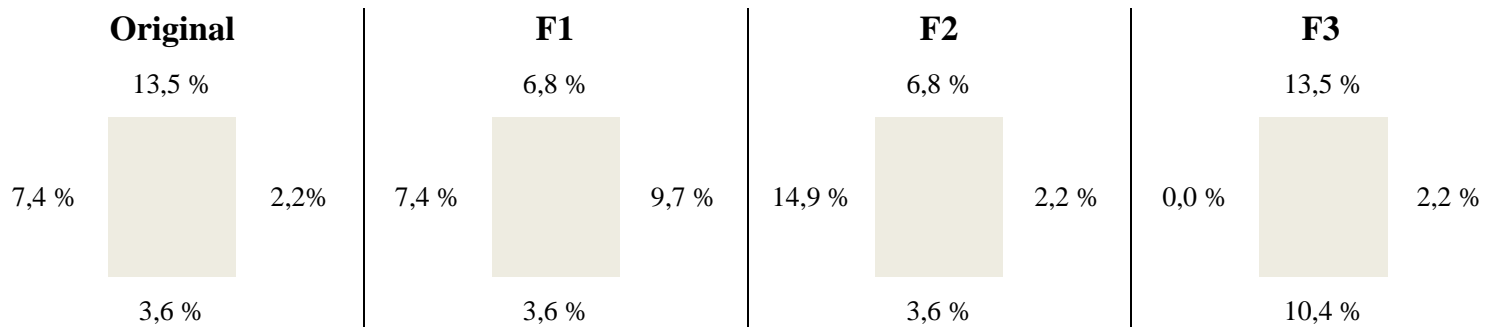

Fonte: DOERFLER (2014) 
Figura 5 - Planta com diferentes orientações (cada $45^{\circ}$ ) da fachada com maior WWR (\%)
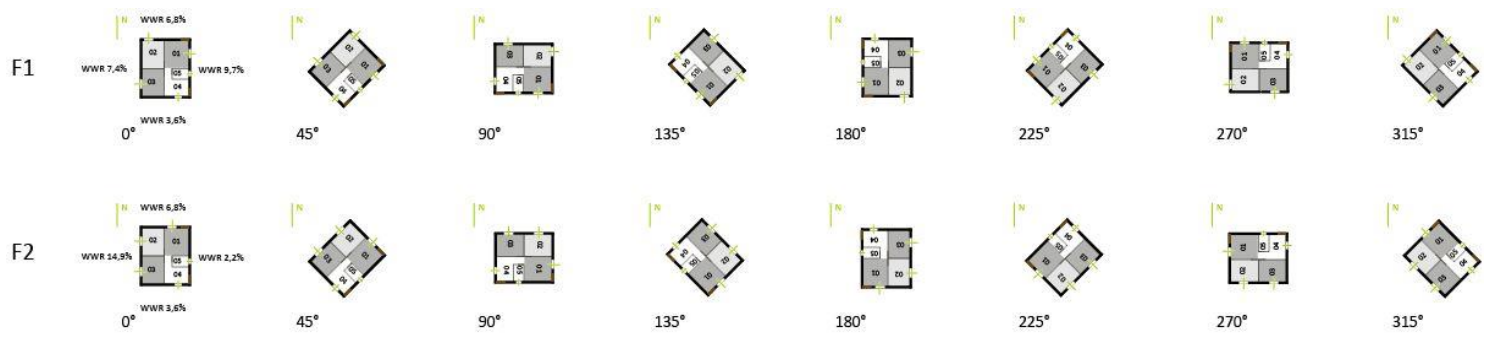

$315^{\circ}$
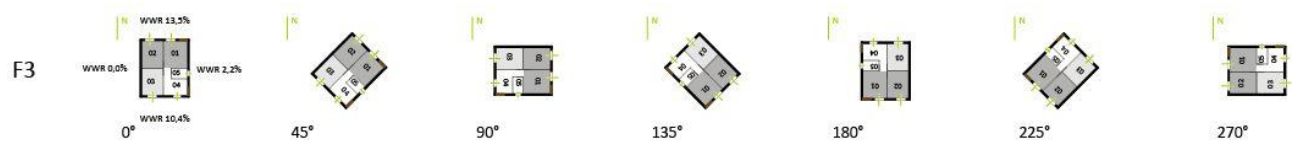

Fonte: DOERFLER (2014)

Gráfico 2 - Síntese dos Resultados/Diferenças percentuais em termos de necessidades de aquecimento em relação à pior situação, considerando reposicionamento das aberturas de $45^{\circ} \mathrm{em} 45^{\circ}$

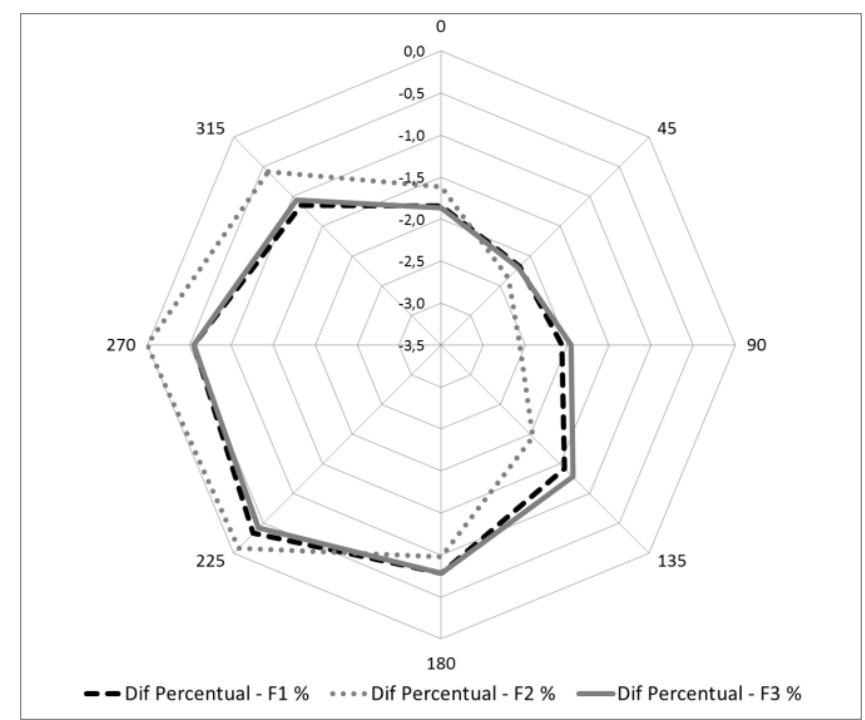

Fonte: DOERFLER (2014)

\begin{tabular}{|c|c|c|}
\hline $\begin{array}{c}\text { Gráfico 3-Percentuais } \\
\text { relativos em termos de } \\
\text { necessidade de aquecimento }\end{array}$ & $\begin{array}{c}\text { Gráfico 4-Percentuais } \\
\text { relativos em termos de } \\
\text { para reossidade de aquecimento } \\
\text { proção do }\end{array}$ & $\begin{array}{c}\text { Gráfico 5-Percentuais } \\
\text { relativos em termos de } \\
\text { pecessidade de aquecimento } \\
\text { para reorientação do } \\
\text { para reorientação do } \\
\text { projeto versus }\end{array}$ \\
$\begin{array}{c}\text { projeto versus } \\
\text { reposicionamento das } \\
\text { aberturas F1 }\end{array}$ & $\begin{array}{c}\text { reposicionamento das } \\
\text { aberturas F2 }\end{array}$ & $\begin{array}{c}\text { reposicionamento das } \\
\text { aberturas F3 }\end{array}$ \\
\hline
\end{tabular}




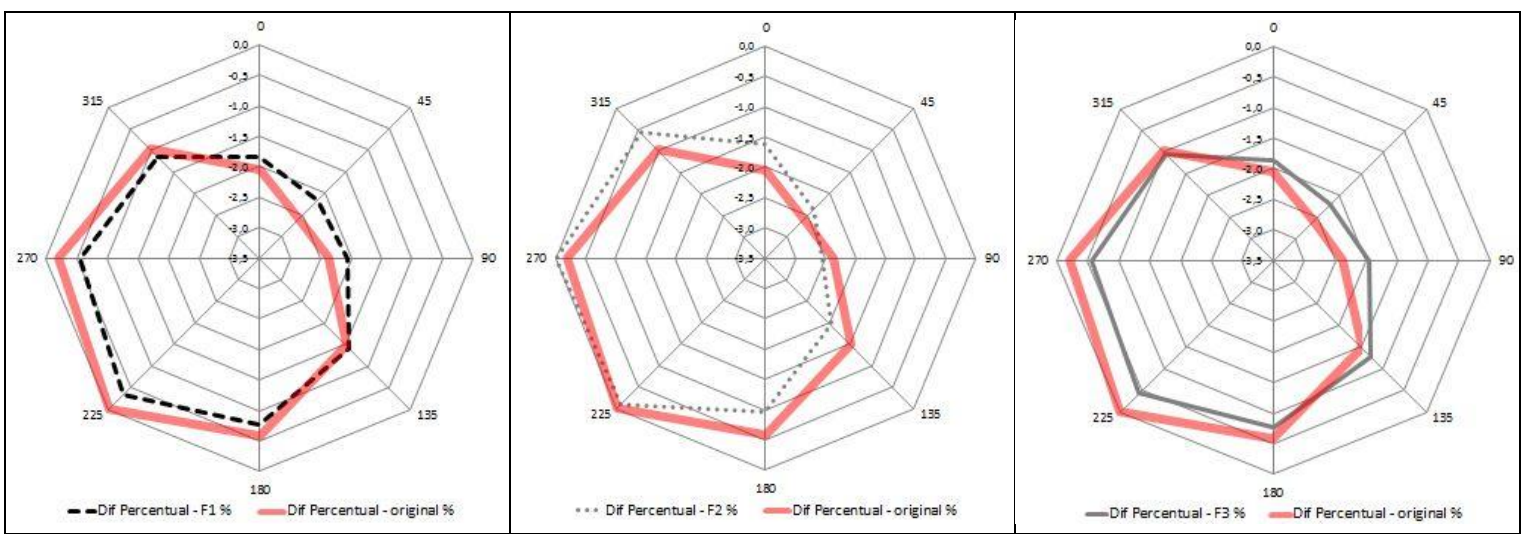

Fonte: DOERFLER (2014)

\subsection{Relação entre WWR e demanda energética para aquecimento}

O Gráfico 6 é uma tentativa de explicitar a relação entre o WWR da fachada com maior insolação no período do inverno $(\mathrm{N})$ e a demanda energética para aquecimento da moradia. Neste caso, não são consideradas as orientações em diagonal da fachada principal. Ao gráfico foi acrescentada uma linha de tendência, cujo valor do coeficiente de determinação é baixo. A correlação encontrada (o valor R) foi de 0,52 , o que mostra que existem outros fatores interferindo na relação WWR por fachada insolada vs. demanda energética, como, por exemplo, a ação do vento na edificação, o formato retangular da edificação, etc. Entretanto, o pior e o melhor caso estão representados no gráfico segundo a tendência verificada.

Gráfico 6 - Relação entre percentual de área de abertura para Norte e demanda energética anual para aquecimento

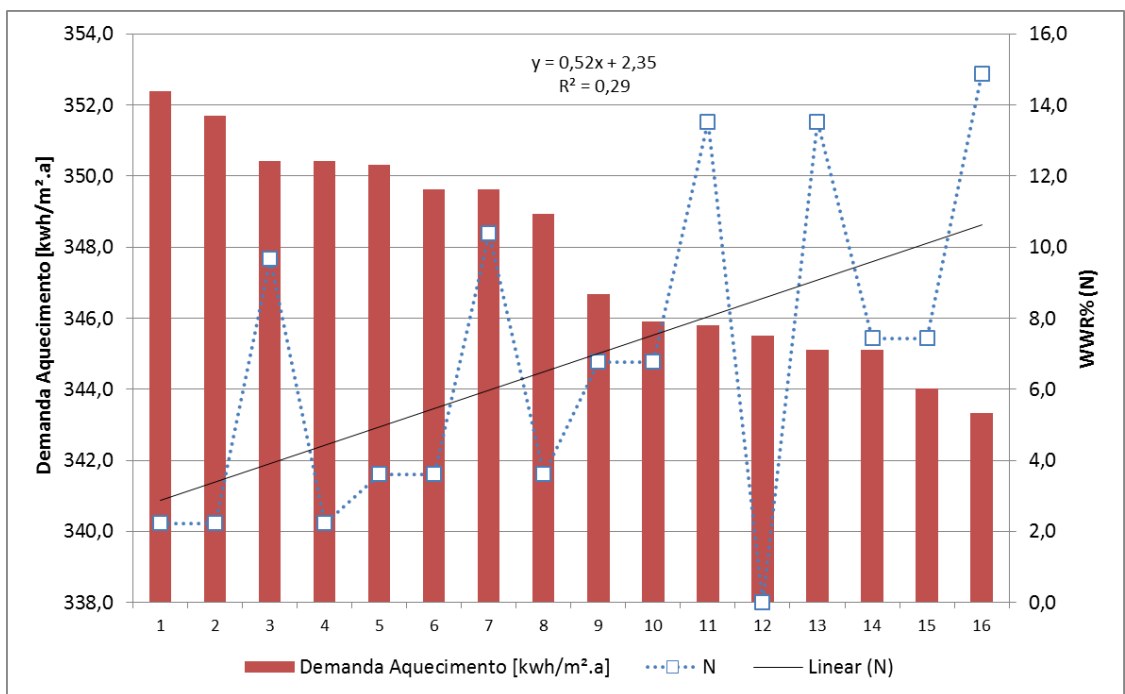

Fonte: DOERFLER (2014) 


\section{CONSIDERAÇÕES PARA O PLANEJAMENTO DE EDIFICAÇÕES E CONJUNTOS HABITACIONAIS}

Alguns pontos principais podem ser ressaltados a partir dos resultados obtidos para Curitiba:

- Caso o loteamento não tenha ainda definição dos lotes e das vias, a opção para o projeto original, do ponto de vista da implantação, seria para o quadrante N-E;

- Para condições mais específicas de orientação de eixo das vias, os resultados podem ser aplicados na escolha do melhor posicionamento possível das aberturas para aquela orientação da edificação (para tanto, os Gráficos 3-5 podem nortear a escolha por uma realocação das aberturas).

\section{CONCLUSÕES OU CONSIDERAÇÕES FINAIS}

Este estudo mostrou pequenas reduções no consumo de energia em função de alterações na orientação do projeto e no reposicionamento das aberturas. Embora os valores sejam relativamente baixos, recomendações neste sentido podem nortear a implantação de conjuntos habitacionais.

Outro fator a ser considerado no caso específico de Curitiba diz respeito ao acesso solar, conforme recomendações do Zoneamento Bioclimático Brasileiro. Havendo essa necessidade, o Gráfico 6 assume uma maior importância, devendo-se levá-lo em conta na definição da implantação da moradia.

\section{REFERÊNCIAS}

ASSOCIAÇÃO BRASILEIRA DE NORMAS TÉCNICAS (ABNT). NBR 15220: Desempenho térmico de edificações, 2003.

NBR 15220-3: Desempenho térmico de edificações - Parte 3: Zoneamento

bioclimático brasileiro e diretrizes construtivas para habitações unifamiliares de interesse social, 2003.

BRASIL. Lei n.․ 11.977, de 7 de Julho 2009. Dispõe sobre o Programa Minha Casa, Minha Vida - PMCMV e a regularização fundiária de assentamentos localizados em áreas urbanas. Disponível em: < http://www.planalto.gov.br/ccivil_03/_ato2007-2010/2009/lei/111977.htm>

CAIXA GIDUR/VT. Cadernos CAIXA Projeto padrão casas populares, 2006. Disponível em: http://downloads.caixa.gov.br/_arquivos/banco_projetos/projetos_his/casa_42m2.pdf

D’AMICO, Fabiano. O Programa Minha Casa, Minha Vida e a Caixa Econômica Federal. Centro Celso Furtado, 2011. Disponível em:

http://centrocelsofurtado.com.br/arquivos/image/201109261251530.LivroCAIXA_T_0_033.pdf

DOERFLER, M. Estratégias para a otimização do conforto ambiental e do gasto energética da arquitetura residencial do Brasil. Dissertação ainda não publicada. 2014.

MORI, F ; KRÜGER, E.L. Análise da eficiência energética da envoltória de um projeto padrão de uma agência bancária em diferentes zonas bioclimáticas brasileiras. Ambiente Construído (Online), v. 12, p. 89-106, 2012.

SEN, Amartya Kumar. Desenvolvimento como liberdade. São Paulo, Companhia das Letras, 2007.

U.S. DEPARTMENT OF ENERGY. EnergyPlus Energy Simulation Software: Weather

Data. 2011. Disponível em:

http://apps1.eere.energy.gov/buildings/energyplus/weatherdata_about.cfm 